Article

\title{
Ethnic/Racial Terminology as a Form of Representation: A Critical Review of the Lexicon of Collective and Specific Terms in Use in Britain
}

\author{
Peter J. Aspinall
}

Centre for Health Services Studies, University of Kent, Canterbury CT2 7NF, UK; P.J.Aspinall@kent.ac.uk

Received: 18 July 2020; Accepted: 17 August 2020; Published: 20 August 2020

\begin{abstract}
All ethnic/racial terminology may be seen as a form of representation, whereby meanings are generated by a range of social categorizers in settings of popular culture, political discourse, and statistical governmentality. This paper investigates these representations through a critical review of the lexicon of collective and specific ethnic/racial terms in use in Britain. Relevant studies and documents were identified through structured searches on databases of peer-reviewed literature and the websites of government census agencies. The full-text corpus of the UK Parliament was used to delineate the genealogies or etymologies of this terminology. The derivation of specific ethnic/racial terms through census processes tends to conform with the theoretical model of mutual entailment of social categories and group identities. This relationship breaks down in the case of the broad and somewhat abstract categories of race/ethnicity originating in the modern bureaucratic processes of government and advocacy by anti-racist organizations, opening up a space for representations that are characterized by their exteriority. Commonly used acronyms are little understood in the wider society, are confusing, and of limited acceptability to those they describe, while other collective terms are offensive and ethnocentric. Accurate description is recommended to delineate ethnic minority populations in terms of their constituent groups.
\end{abstract}

Keywords: ethnicity; race; terminology; representations; acronyms; social category; group identity

\section{Introduction}

It is arguable that all ethnic/racial terminology is a form of representation, given the diverse ways in which such terminology comes into being, its frequently racialized expression, and its ubiquitous use. These characteristics yield a space where multiple and alternative meanings of this terminology are produced. The complexity of the lived experiences of different communities and the role of power and authority in how this terminology comes to be used provides fertile ground for the generation of these meanings in popular culture, political settings, and statistical governmentality. These processes are not unidirectional but feed back upon each other, belying the description of terminology for minority and majority ethnic/racial groups as multiple, contested, contentious, dynamic, and slippery. Moreover, this terminology may encompass collective terms for large segments of the population, as well as specific terms for particular ethnic/racial groups.

A clear line of cleavage (though in some cases of mutual reinforcement) is that between the terminology communities may choose for themselves as self-descriptors, and that which people and institutions outside the group apply to them. At times of tension between these two dialectics of representation, communities may set up their own affinity groups, informal organizations, or movements to represent their views and articulate their preferences. In other circumstances, they may be conscripted by racial justice advocates into inclusion in collective terminology without their active involvement, in the interests of creating a voice of unity and solidarity and signalling a 
location in the concept of 'race'. The decennial census and its terminology is a further powerful form of representation, both in itself and with respect to the ethnic/racial diversity in the population that it reveals. For example, the 1990 US Census schedule used the term 'Asian and Pacific Islander' (API) that stuck as a social category until dropped in the 2000 Census. Like identity itself, ethnic/racial terminology changes over time in response to shifting preferences in the wider society, the changing composition of the population, and changing patterns of racialization.

Ethnic/racial terminology as a form of representation has attracted only limited attention as a site of scholarly investigation. It was Edward W Said, in his 1978 book Orientalism, who brought the genre of social representation to wider public attention. In describing 'Orientalism as a Western style for dominating, restructuring, and having authority over the Orient' (Said 2003, p. 3), he noted that 'the principal product of this exteriority is of course representation' (p. 21). In turn 'any and all representations, because they are representations, are embedded first in the language and then in the culture, institutions, and political ambience of the representer' (p. 272). Similarly, Kobayashi (1993), writing on 'representing ethnicity' in Canada, draws on the claim that 'all representation is an ideological product by which those in power or those who would wield power-including social scientists and other commentators upon social phenomena-ideologically construct (and re-construct) a realm of meaning through the process of re-presentation' (p. 513). In Britain Stuart Hall has developed the field of 'cultural representations', particularly with respect to race, ethnicity, and gender, describing such representations as 'an essential part of the process by which meaning is produced and exchanged between members of a culture' (Hall 1997).

Such processes conform with Jenkins (1996) basic theoretical model of the internal-external dialectic of identification, whereby group identities (as constituted by members of the group) and social categories (the collective external definition by others) are mutually implicated in and feed back upon each other. The internal-external dialectic of identification and labelling theory are used as a framework to explain the consentient or conflictual nature of terminology. The usage of any ethnic/racial label is a complex outcome of the interaction between observers, officialdom, and the wider society (the 'social categorizers') and those whom the label describes (the 'group identifiers'). In the case of 'labelling theory', the interaction between (external) definition by others and (internal) self-definition is described as a process of internalization. Jenkins links the process to authoritative labelling and its consequences, whereby the power of the labeller impinges on individual experience. Another identity effect might be resistance.

With reference to this conceptualization of ethnicity as social identity, the role of social categorizers (or observers) is undertaken by a wide variety of actors. Government population census and statistical agencies-the Office for National Statistics (ONS) in England and Wales-play a key role. As a result of extensive research and testing, census ethnic group terminology and categories rapidly gain the status of a gold standard and are adopted (and sometimes mandated) for use by wider government. Data based on the census enumeration are also designated as 'official statistics'. By such means, the census categories come to be used for the collection, construction, and reporting of a wide range of official statistics, including those in the fields of education, housing, health, the labour market, and criminal justice. This embeddedness in official discourse, policy formulation, policy implementation, and wider processes of administrative allocation gives the terminology an authority and acceptance. This may also apply to pronouncements by bodies such as the ONS and UK Statistics Authority on other ethnic/racial terminology with respect to acceptability. Census classification and categorization may gain further traction through public rhetoric and, at an individual level, in their everyday use in the completion of forms that ask for ethnic group.

However, social categorization-any identification of others as a collectivity-may also be undertaken with varying effectiveness by many other actors, including institutions, the media, the wider society, and members of an ethnic group ('others' as opposed to co-members). The extent to which categorization may affect group identities or internal definition clearly depends on the power or authority wielded by these actors and the role of minority ethnic communities in shaping the 
terminology that is used for describing them. In this era of self-ascription, where the participant is acknowledged as the final arbiter of their ethnic group, categorization has contributed to group identity more through legitimate authority than power. External categorization is now frequently the same as or similar to existing group identities and mutually reinforcing. Where groups define themselves somewhat differently to social categorizers, they may still be prepared to use the externally defined social categorization in spite of its partial meaningfulness for them. For example, 'mixed race' is the salient term as a group identifier, though census practice has dissociated 'mixed' from 'race' in adopting the terms 'mixed'/'mixed/multiple'.

This mutual entailment of social categories and group identities tends to break down when we consider very large identity categories, be they the antagonistic binary oppositions of the past or the convenient, shorthand labels of the present. Throughout much of the early twentieth century, these broad categories of race derived by categorizers were expressed and understood as 'Manichean cultural dichotomies' (Cannadine 2013, p. 7, citing historian Timothy Garton Ash): 'Occidental' vs. 'Oriental', 'pure race' vs. 'half-caste', 'Coloured' vs. 'White', 'Britishness' vs. 'Otherness', to name a few. While much of this pejorative terminology has been leached out of the lexicon in recent decades, vestiges persist in settings where those described by it lack power. For example, the term 'half-caste' (Aspinall 2013) continues to be used as a social category in some schools, youth detention centres, and prisons. 'Oriental' has lingered on in some health datasets as a descriptor of those with origins in the Far East. Indeed, as late as the 1970s, in the early days of government social and general-purpose surveys, it was the interviewer who determined the ethnic group of the participant through observer assignment, a process finally abandoned in the General Household Survey in 1983.

Broad categories of race/ethnicity also have their origins in the modern bureaucratic processes of government, in particular, the need for a shorthand term to identify those who experience discrimination on the grounds of their skin colour or phenotype. Similarly, those who advocate for racial equality and justice have devised their own terminology, largely independent of government and sometimes with the limited involvement of the communities they seek to represent. Such terminology represents a form of solidarity and means of drawing unity. In both cases, this terminology's use of sometimes capacious social categories may have only limited saliency amongst minority ethnic groups. Clearly, terminology to describe collectivities frequently embodies a number of pan-ethnicities, and so is not specific to any one ethnic group. This may create social distance between particular ethnic groups and their external definition in more global terms, and may thus have less bearing on lived experience.

The main aim of this paper is to critically review the various forms of representation that characterize the lexicon of collective and specific ethnic and racial terms in use in Britain. This includes the use of acronyms (BME: 'Black and Minority Ethnic' and BAME: 'Black, Asian, and Minority Ethnic') as collective terms, other collective terminology such as 'people of colour', pan-ethnicities like 'Black' and 'Asian', and specific ethnic groups. This analysis finds that commonly used acronyms are little understood in the wider society, are confusing, and of limited acceptability to those they describe. Other collective terms such as 'Non-White' and 'Oriental' are offensive and ethnocentric. Accurate description is recommended to delineate ethnic minority populations in terms of their constituent groups.

\section{Results}

This section presents the main findings of the study with respect to both collective and specific terms.

\subsection{The Use of Acronyms (BME and BAME) as Collective Terms}

It is now almost twenty years since the collective terminology for minority ethnic/racial groups in Britain was evaluated (Aspinall 2002). At that time, the acronym BME ('Black and Minority Ethnic') was gaining in saliency, while BAME ('Black, Asian, and Minority Ethnic') had already made its entrance, making it a matter of urgency to subject such terms to critical appraisal. These acronyms 
were found to be inconsistently used by agencies with respect to capture. Moreover, their illogical construction (suggesting that 'Black' and 'Asian' are not minority ethnic groups) and the ambiguity of 'minority ethnic' itself made for awkward interpretation. More recently, there have been efforts to popularize additional acronyms, such as 'AAME' ('African, Asian, and Minority Ethnic') ${ }^{1}$, but few have embraced such new terms.

It was hoped that with this critique, the usage of these acronyms would wane and that commentators would, instead, resort to 'the use of accurate description to delineate the ethnic minority (or minority ethnic) population in terms of the constituent groups' (Aspinall 2002, p. 812). Instead, such terminology has undergone an ascendancy in usage. The term BAME has been adopted by many organizations concerned with race equality, such as the Institute of Race Relations, Business in the Community, Race on the Agenda, and others in the third and private sectors. Most civil service departments use the BAME acronym. Nowhere has this growing usage been more apparent than in the focus by government and agencies over recent months on the greater risks experienced by Black and Asian groups in Britain in the coronavirus pandemic. Now, government public health agencies talk about 'BAME populations', 'BAME groups', 'BAME communities', 'BAME people', 'BAME households', 'BAME staff', and just 'BAME' (as a noun), counting as what Hacking (1986) termed 'kinds of person', brought into being by the creation of labels for them. One recent Public Health England report mentioned BAME around fully 220 times without defining the term other than spelling out the acronym (Public Health England 2020). Indeed, in this particular case, those who self-identified as, say, 'Indian', in hospital records now find themselves reassigned to the collective 'BAME' category, thereby privileging administrative processes over the claims of, and respect for, individual identities.

In the literature on racial/ethnic disparities and inequities and structural or systematic racism, this language provides a convenient shorthand for those who experience disadvantage or are discriminated against by virtue of their physical appearance or skin colour (a collectivity similar to that defined in a Canadian context as the 'visible minority' population). It is an artefact of the bureaucratic processes of government and of administrative efficiency. Yet the growing popularity of these terms is likely to sustain their continued usage, as acknowledged by the addition of 'BAME' to the Oxford English Dictionary's 'New words list' in $2014^{2}$, six years after the appearance of 'BME' in the 2008 list.

The genealogies or etymologies of these racialized terms throw some light on their origins and growth in discourses about structural racism and other disadvantage. An appropriate source of information on secular trends in usage is the record of the proceedings of the House of Commons and House of Lords in the UK Parliament (Commons and Lords Hansard). The term 'Black and Minority Ethnic' first occurred in 1987 and had appeared 1222 times by June 2020 (Figure 1), making it the prevalent term over this time span. Its use was limited to under ten instances a year until 1999. Thereafter, the count gradually increased, with peaks in $2007(n=97)$ and $2016(n=138)$, followed by a decline to $2020(n=75)$. The term 'Black, Asian, and Minority Ethnic' had a much later debut, making its first appearance in 2004, and registering 333 occurrences by June 2020. Usage was sporadic (ten or less cases) until 2015, rising to a peak of 88 in 2020, the year in which it overtook 'Black and Minority Ethnic'.

1 Nuamak K. BAME Advocates African Identity Group, Which Acknowledges an MP and a Community Group for Using AAME. 25 May 2020. Accessed online: http://taobq.blogspot.com/2020/05/blam-pow-bame-advocates-african.html.

2 https://public.oed.com/updates/new-words-list-june-2014/. 

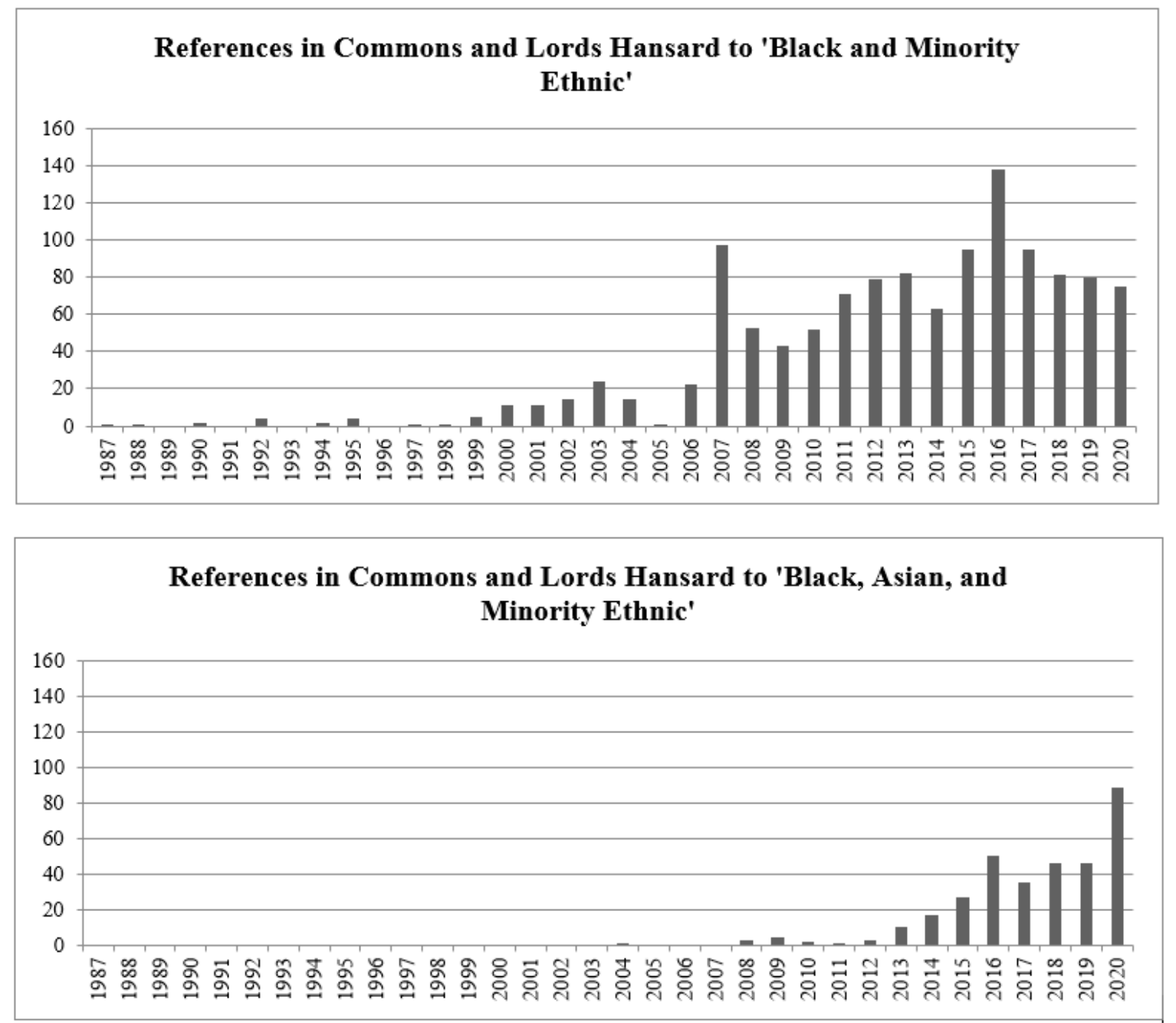

Figure 1. References in UK Parliament Hansard to 'Black and Minority Ethnic' (BME) and 'Black, Asian, and Minority Ethnic' (BAME). Note: 2020 data is for January-June only.

While the above data shows a genesis for 'BME' in the UK Parliament in the late 1980s, recent investigators suggest that the acronym first gained currency earlier in this decade among local authorities with large populations which were other than White: 'These councils were at the forefront of the equality debate after the Scarman Report-commissioned in response to the 1981 Brixton riots-called for "urgent action" to address racial disadvantage and inner city decline. The rationale for the term was that it was important to retain the use of Black for its political effectiveness, but add Minority Ethnic because census data showed that minority communities were becoming more ethnically diverse' (Saeed et al. 2019). Indeed, the 1991 Census, the first to ask a question about ethnic group, showed that while the Black groups (Black-Caribbean, Black-African, and Black-Other) comprised 2.0\% of the population of England and Wales, the South Asian groups (Indian, Pakistani, and Bangladeshi) exceeded this at $3.1 \%$.

Several factors may have led to the emergence of the 'BAME' acronym in the early 2000s and its rise to prominence in 2020. The 2001 Census showed a widening gap between the Black and Asian groups with respect to their shares of the England and Wales population, the Black groups having grown to 2.2\%, but the three Asian groups to 3.9\%. Moreover, the Fourth National Survey of Ethnic Minorities (Modood et al. 1997) showed that Asians and Chinese did not feel that the political term 'black' - a community in solidarity against racism-included them. Both these factors called for a new collective descriptor that explicitly included Asians. These arguments were supported by scholars who started using the new term in published papers from the late 1990s/early 2000s, and by the then Commission 
for Racial Equality and Institute of Race Relations. It gained traction as an all-inclusive term during the first two decades of the new century. Its achievement of dominance in the first six months of 2020 may well be related to the almost ubiquitous use of 'BAME' in government departmental reports about the greater risks experienced by Black and Asian groups in the COVID-19 pandemic. Indeed, a search of the GOV.UK portal-the website for the UK Government launched on 1 February 2012 and hosting all ministerial departments by 1 May 2013 - revealed that, for records published since January 2010, results for 'BAME' substantially exceeded 'BME' (428 vs. 242), the gulf widening as the decade progressed, now making it the government's collective term of choice for minority ethnic groups.

The continued use of this terminology by government-and, indeed, the increasing saliency of 'BAME'-is surprising given the advice in government style guides to eschew such acronyms. That for the Race Disparity Audit's Ethnicity Facts and Figures website ${ }^{3}$ indicates that the acronyms BAME and BME are not used. In its related Writing about ethnicity guide ${ }^{4}$ it gives the reasons: 'The UK's ethnic minorities include White minorities; they highlight some groups and not others-for example, Black and Asian people are included but not people of a Mixed ethnicity; and in user research, the acronyms BAME and BME were not well understood by our audience'. The Office for National Statistics House style guide ${ }^{5}$ states: 'Use terms like "ethnic minority", "ethnic minorities", "ethnic minority population(s)", and so on, instead of acronyms such as BME and BAME, which are frequently used to refer to all except the White ethnic group. This is to avoid highlighting particular groups above others'. This advice from the government's Cabinet Office and the country's official statistics agency (also a non-ministerial government department) is authoritative yet not complied with by other government departments and their executive agencies.

Clearly, not all minority ethnic groups are discriminated against on the grounds of phenotype, so the 'Minority Ethnic' coat-tailed on to the acronym is confusing with respect to coverage. Throughout the twentieth century, the category which the decennial census terms 'White Irish' has experienced persistent racism, and this is also true in recent decades of communities of Poles, Bulgarians, Romanians, and other East and South European population groups. When the Lammy Review reviewed the treatment of, and outcomes for, minority ethnic groups in the criminal justice system, it had to define 'BAME' in its glossary as: 'Black, Asian and Minority Ethnic-this report has also considered the treatment and outcomes for Gypsies, Roma and Travellers and Muslims. This is due to their significant over representation in the criminal justice system' (Lammy 2017). Bunglawala (2019) expresses the ambiguity thus: ' $\ldots$ the terms 'BAME' and 'BME' are not always associated with White ethnic minorities such as Gypsy, Roma and Traveller of Irish Heritage groups, which we know are among some of our most marginalised and disadvantaged communities. To leave these communities out of the very language we use is to marginalise them even further'. In addition, as noted, the Irish frequently get omitted in this category shuffle.

The difficulty with this collective terminology is that it tends to be developed-and subsequently popularized and sustained-by observers, such as government bodies, public and statutory agencies, and the media. It is not the outcome of a discursive and interactive process involving its developers and the people the terminology describes. This is particularly exemplified by the case of BAME and BME. User testing and research undertaken by the government's Race Disparity Audit, on the use of terminology relating to ethnicity, found that amongst nearly 300 people across the UK, only two $(<1 \%)$ recognized the acronyms, and only one knew in general terms what they stood for (Bunglawala 2019). By contrast, the Government Digital Service style guide ${ }^{6}$ on the use of an abbreviation or acronym asks

3 Style guide: Guidance on writing for the Ethnicity facts and figures website and publications. Accessed at: https: //www.ethnicity-facts-figures.service.gov.uk/style-guide.

4 Writing about ethnicity. Accessed at: https://www.ethnicity-facts-figures.service.gov.uk/style-guide/writing-about-ethnicity.

5 Office for National Statistics. Language and Spelling. Accessed at: https://style.ons.gov.uk/category/house-style/languageand-spelling/\#race-and-ethnicity.

6 The Government Digital Service. Style guide. Accessed at: https://www.gov.uk/guidance/style-guide/a-to-z-of-gov-ukstyle\#abbreviations-and-acronyms. 
users to provide evidence, from search analytics or testing of a representative sample, 'that $80 \%$ of the UK population will understand and commonly use it'. Such low indices of recognition underline the difference between internal and external definition, and will clearly affect the public's understanding of government reports that use these acronyms.

Moreover, there is some evidence from a synthesis of opinion pieces, posts, and blogs that acronyms like BAME and BME have only limited acceptability amongst those described by them. The dissatisfaction with the terminology focuses on several attributes. As collective terms, they imply that the individuals captured by these terms are a homogeneous group. Moreover, they single out and name specific pan-ethnicities ('Black' and 'Asian'), raising issues of exclusion and divisiveness. They are labels devised by agencies, the media, and other observers that are used to categorize people belonging to minority ethnic groups rather than group identifiers that have come about through processes of internal definition. Finally, although the acronyms encompass 'minority ethnic', they are widely understood to exclude White minority ethnic groups. Typical of such viewpoints is that of Black British Academics: "The terms "BME" and "BAME" should be problematized since they homogenise people from a variety of different ethnic and cultural backgrounds and reproduce unequal power relations where White is not a visible marker of identity and is therefore a privileged identity ... they mask inequalities as they are experienced by different racialised ethnic groups. The use of these terms reinforce racial inequality by maintaining White ethnic identity as privileged. Since 'White' is never named as an identity, it continues to be normative so that people of colour only exist in a marginalised position that is de-centred by whiteness' ${ }^{7}$.

\subsection{Other Collective Terms}

Against this proliferation of abbreviated and compound terms, the label 'ethnic minority' (or 'minority ethnic') retains some support. Some twenty-five years ago, Modood et al. $(1994$, p. 1) wrote that the 'use of the term "ethnic minority" has increased and is pervasive'. Since then, the term continues to be widely used in academia and by public agencies. Some users prefer to privilege the term 'minority ethnic' as its construction acknowledges that everyone belongs to an ethnic group, including those groups categorized as White. In addition to indicating populations that are not the (numerical) majority in a particular country or other geography, these terms may also invoke relative positions of power in the society. Both the Race Disparity Unit (Cabinet Office) and Office for National Statistics favour this terminology. However, care is required in the usage of these terms (their reference to 'minority') in the context of the changing ethnic diversity of the country. In Britain, minority ethnic groups are increasingly being defined as all Census ethnic groups other than 'White British', that is, including White minority ethnic groups such as 'Irish', 'Gypsy or Irish Traveller' and those of 'Any other White background'. The 2011 Census revealed that in England and Wales, there were two plural local authority districts where 'White British' was not the largest group. By 2021 the number of such districts is projected to increase to 15 (Jivraj and Simpson 2015).

'Minority' has a somewhat different meaning in US literature, where it is frequently used to describe a group historically subject to economic exploitation and racial discrimination. 'Ethnic minority' is a much more common term than 'minority ethnic', aligning with terms for other kinds of minorities, such as sexual identity minority, religious minority, and gender minority. There are other differences between British and American terminology with respect to the construction of the encompassed ethnicities. Some in the South Asian groups identify themselves as, for example, 'British Asian', 'British Indian', and 'British Bengali', placing emphasis on the diaspora of the individual's country of origin. By contrast, in the US context, the comparable usage would be 'Indian American', 'Indian' being the modifying adjective and 'American' the noun. In the US, the privileging of the

7 Black British Academics. Racial Categorisation and Terminology. Accessed at: https://blackbritishacademics.co.uk/about/ racial-categorisation-and-terminology/. 
national identity may be driven by notions of US exceptionalism, integrated assimilation, and of the 'melting pot'. However, it is noteworthy that in Britain, ONS uses the terms 'Asian British' and 'Black British' in the census pan-ethnicities or section labels. Further, many of the children of Black Caribbean parentage prefer a self-description of 'Black British'.

The use of 'non-white', another shorthand collective term that in this case explicitly refers to ethnic groups other than white, is widely and — given its brevity and convenience-unquestioningly used, including by ONS (albeit infrequently), by government departments, and in scholarly writing (though with some notable dissenters, such as Madowitz and Boutelle 2014). An exception is the Cabinet Office which declares: 'We do not use 'Non-White' because defining groups in relation to the White majority was not well received in user testing' ${ }^{\prime}$. Indeed, the term 'non-Black' is never used when describing the White group. 'Non-white' defines the ethnic minority population in negative terms-by what it is not-and as a residual population. Further, it sets 'white' as the standard, making it openly ethnocentric, and reinforces 'the myth of homogeneity' of the white group, excluding from the term white minority ethnic groups. These drawbacks invite some reflexivity on its employment, notably, its quotidian use by the majority ethnic group, thereby affirming a norm of dominance. In the USA, the 1977 Statistical Directive 15 on race and ethnic standards for federal statistics and administrative reporting — and the 1997 revisions to this standard—stated that the designation 'nonwhite' was not acceptable for use in the presentation of Federal Government data and was not to be used in any publication or in the text of any report.

'People of colour', 'women of colour', and 'communities of colour' are other collective terms that have been developed largely outside government for describing racial groups other than White. Their use appears to depend strongly on context and location, being popularized in, but largely confined to, the USA since the 1970s (alongside the term 'black') and increasingly in a radical political context. They have also been adopted by the alternative politics of Canada (Bannerji 2000), but show little saliency in Britain with its emphasis on racialized ethnicity. For example, they were used only 44 ('people of colour') and 28 times ('women of colour') in Parliament's Hansard between 1987 and 2020 (mainly since 2015). Such terms are not used by the Office for National Statistics and are almost completely avoided by government departments, appearing only 11 times on GOV.UK, the portal to online government documentation.

'People of colour' terminology has its advantages and drawbacks. Racial justice advocates argue that they are politically useful terms to address racial inequities as they provide an inclusive and unifying frame of reference. Moreover, they describe people with reference to their own attributes rather than by language that states what they are not, as is the case with the term 'non-White' ${ }^{\prime}$. Likewise, the term excludes the word 'minority' that confers a subordinate status on people who are not White. Critics point out, however, that like collective terms as a whole, these terms suggest that minority ethnic groups are a unified group characterized by homogeneity, whereas analysts emphasize the importance of focusing on the identity of people through their own specific racial/ethnic groups. Yuen (1997) objects to the use of the term on the grounds of its demarcation of difference rather than commonality even though people of colour are a global majority, but concludes that the persistence of white racist ideology validates the use of the term as a discursive and political necessity.

By contrast, the terms 'coloured' and 'coloured people' are pejorative and widely regarded as unacceptable in Britain. When Trevor Phillips, then head of the Commission for Racial Equality, had posed the question 'Is it really offensive to call someone "coloured"?' in a speech in 2005, the view was affirmative. Similarly, in 2015 the London-born and internationally recognized actor Benedict Cumberbatch's use of the word 'coloured' during a US television interview about racial equality in acting resulted in an outcry online and in the media.

8 Style guide: Guidance on writing for the Ethnicity facts and figures website and publications. Accessed at: https: //www.ethnicity-facts-figures.service.gov.uk/style-guide.

9 Race Equity Tools: Glossary. Accessed at: https://www.racialequitytools.org/glossary\#people-of-color. 
A few additional terms have been suggested, such as 'racialized minorities' and 'visible minorities'. Black British Academics endorses the term 'racialized minorities' as it 'draws attention to the racialisation of people of colour and serves to highlight the discursive power of whiteness. As such the term is a critique of whiteness and therefore a form of resistance ${ }^{10}$. Yet, as Bradby (1995, p. 412) notes, 'the experience of discrimination is not dependent on being a minority with dark skin, as an examination of the history of the Irish in Britain shows'. 'Visible minority/minorities', a term that came into common government use in Canada in the mid-1980s (Pendakur 1993), is infrequently used in Britain, registering only 24 occurrences in Parliament's Hansard over the period 1987-2020 and none in a UK.GOV search. The Canadian Race Relations Foundation even suggests that it has limited acceptability in Canada as a group identifier: 'Although it is a legal term widely used in human rights legislation and various policies, currently the terms racialized minority or people of colour are preferred by people labelled as "visible minorities" $" 11$.

\subsection{Pan-Ethnicities and Specific Ethnic Groups}

Both pan-ethnicities in the BAME acronym-'Black' and 'Asian'-present substantial difficulties with respect to definition. The term 'black' began to be used in the 1960s by sociologists and anti-racists to reference the common status of being in a group disadvantaged by racial discrimination prompted by phenotypical differences (sometimes referred to as 'political blackness'). However, in the 1970s, 80s, and 90s, the term was criticized by those it described on the ground of lack of acceptance by these communities and the politically coercive nature of this usage. In 1994, the Fourth National Survey of Ethnic Minorities asked South Asian and Chinese participants if they ever thought of themselves as being 'black' (Modood et al. 1997). Around only a fifth of the South Asians $(n=1500)$ answered 'yes' and just one Chinese person out of 118. With respect to the census, 'Black-Caribbean', 'Black-African', and 'Black-Other' were tick boxes in the 1991 Great Britain Census. They were offered again in the 2001 and 2011 England and Wales Censuses under the section labels 'Black or Black British' and 'Black/African/Caribbean/Black British', respectively. ONS has not used 'Black' in the sense of 'political blackness'.

Similarly, the term 'Asian' has been used to encompass different collectivities, notably, persons with South Asian (Indian Sub-continent) origins, and those with continental Asian origins. Since the 'Asian' community in Britain comprised predominantly persons of Indian, Pakistani, and Bangladeshi ethnic origin, 'Asian' came to be used-but not in all contexts—as a synonym for these Indian Sub-continent groups. Clearly, this ambiguity would transfer to the 'Asian' category in the BAME acronym. 'Asian' as a pan-ethnic identity also has limited acceptability amongst those with Indian sub-continent origins, though with varying saliency across Britain (Aspinall 2002). Amongst a diverse group of around 50 South Asian interviewees, Modood et al. (1994) found that more identified with an ethnic or religious identity than with 'Asian'.

This inconsistency in meaning also applies to the decennial census. The first such use of 'Asian' was in the 2001 England and Wales ethnic group question, when it was incorporated into the overarching 'Asian or Asian British' label, encompassing the tick boxes of 'Indian', 'Pakistani', 'Bangladeshi', and write in 'Any other Asian background'. ONS intended this set to capture those with Indian sub-continent origins, the 'Chinese' tick box being included in the 'Chinese or other ethnic group' section. However, in the 2001 Scotland Census, the 'Chinese' tick box was located under the 'Asian, Asian Scottish, or Asian British' banner along with the other four groups, making Asian a continental descriptor. England and Wales followed suite in 2011, a change that was likely to have affected who used the write-in 'Any other Asian background' option or selected the 'White and Asian' mixed category.

10 Black British Academics. Racial Categorisation and Terminology. Accessed at: https://blackbritishacademics.co.uk/about/ racial-categorisation-and-terminology/.

11 Canadian Race Relations Foundation. Accessed at: https://www.crrf-fcrr.ca/en/resources/glossary-a-terms-en-gb-1?start= 100. 
The third pan-ethnicity on the England and Wales 2001 Census form, 'Mixed' (the other two were 'White' and 'Chinese or other ethnic group'), presented few problems with respect to terminology. ONS eschewed 'mixed race' as the section label, this being the salient term in this population, and also 'dual heritage' or 'mixed heritage', politically correct terms favoured by some government departments. Respondents readily accepted 'mixed' (expanded to 'mixed/multiple' in 2011), the three predesignated tick box options ('White and Black Caribbean', 'White and Black African', and 'White and Asian') self-evidently being 'mixed race' categories.

Interestingly, there is also a similar plurality of terms in the USA. A 1995 survey (Tucker et al. 1996) found 'multiracial' to be the salient term ( $28.4 \%)$, followed by 'mixed-race' $(16.0 \%)$, but with 'biracial' lagging behind $(5.7 \%)$. More than a quarter of respondents had no preference. The saliency of 'multiracial' as a self-descriptor came about through the multiracial student movement (the generation born in the late 1960s and early 70s following the Loving vs. Virginia decision), and the 1990s campaign to get a 'multiracial' category on the census and other state and federal forms. 'Mixed race' was more an importation from the UK context where a movement of scholarship and student activism had popularized the term (Joseph 2013). The US Census Bureau uses the entirely different term 'the two or more races population'.

There is no explicit collective category in the decennial census for people with origins in South East Asia (the Far East), only a specific category for those who identify as 'Chinese'. They frequently refer to themselves by reference to their specific country of origin, such as 'Vietnamese' or 'Malaysian', in free-text fields (notably, 'Any other Asian background'). In the absence of a collective census term, the label 'Oriental' has gained some traction, repurposing the European conception of the wider 'Orient', a cultural enterprise conceived to incorporate the Near East, Middle East, Indian subcontinent, and Far East, to describe only the Far East. In the early 2000s, this Eurocentric and offensive descriptor, 'Oriental', had acquired some saliency in National Health Service and other datasets (Aspinall 2005). Some fifteen years later, a search of NHS resources shows persistence in such usage by NHS ambulance and hospital trusts ${ }^{12}$. 'Oriental' is also retained in clinical terms lexicons such as SNOMED, used in general practice electronic health records. A recent public health glossary of terms on migration, ethnicity, and race judged 'oriental' ('a native or inhabitant of the Orient (East)') 'too general to be useful' but did not comment on the widespread view that it is pejorative (Johnson et al. 2019). In other service areas the Judicial College (2018)'s equal treatment bench book advises that 'the term 'Oriental' should be avoided, as it would usually be seen as offensive'. Transport for London (a public body) has also proscribed the term.

Official condemnation of the term has been more widespread in the USA. The Washington State legislature in 2002 described the term 'Oriental' (as applied to persons of Asian descent) as 'outdated and pejorative' and prohibited its use, mandating that 'Asian' 'must be used to replace outdated terminology'. The New York Governor banned the use of 'Oriental' from all state documents in 2009. In 2016, Barack Obama prohibited the term 'Oriental' from being used in all federal laws (US Congress 2016). There is also some resistance to the use of 'Oriental' in Canada-style guides referring to the term as 'a vestige of European imperialism' and 'at minimum, is vague ${ }^{13}$ —and in European countries ${ }^{14}$.

12 Examples are: SE Coast Ambulance Service: Equality and Diversity. 2011. Accessed at: http://www.secamb.nhs.uk/pdf/ Patient\%20Equality\%20Data.pdf) (requisitioning the police force's Phoenix classification, along with 'Dark European'); East Sussex Healthcare NHS Trust. Patient information. 2017. Accessed at: https://www.esht.nhs.uk/wp-content/uploads/ 2017/06/0266.pdf; the Dudley Group NHS Foundation Trust patient information leaflets (2015); and the Royal Berkshire NHS Trust. Maternity Services Report 2014-2015. Reading: Royal Berkshire Hospital, 2015.

13 New Canadian Media. Ethnic Media and Diversity Style Guide. Accessed at: https://newcanadianmedia.ca/wp-content/ uploads/2019/03/Ethnic-Media-Style-Guide.pdf.

14 In 2016 a French professor took to task the authors of a paper in a medical journal for using the term Oriental Jews', on the grounds that 'in common parlance, the Orient consists of different countries, belonging to North Africa, the Middle East, India, China, Japan, etc.', 'Oriental' being attributed 'to everything that was not "Occidental"'. Oberlin C. Re: Dupuytren's Disease in Oriental Jews. E.D. Sorene, E. Rubinraut-Ophir, D.R. Goodwin, Journal of Hand Surgery 2007; 32E: 543-546. Journal of Hand Surgery 2008; 33E: 397. 


\subsection{Ethno-Religious Terminology}

The 2001 Census introduced a voluntary question on religion, with response options of 'none', 'Christian', 'Buddhist', 'Hindu', 'Jewish', 'Muslim', 'Sikh', and a write-in 'Any other', and this was asked again in 2011. Religious belief is now one of a number of 'protected characteristics' under the Equality Act 2010. The extent to which options such as 'Jewish', 'Sikh', and 'Muslim' should also be acknowledged as ethno-religious identities-all with the potential to be cross-cutting, collective terms-and therefore included as tick boxes in the ethnic group question has been raised. Jews (since 1980) and Sikhs (since 1983) have been classified in British case law as constituting 'racial groups' for the purposes of the Race Relations Acts.

In a topic consultation exercise for the 2021 Census 55 possible new response options were requested, and 'Jewish' and 'Sikh' were amongst the four with highest user need taken forward for further investigation. However, focus group testing for ONS showed that amongst the Jewish population there was a strong consensus that a specific Jewish response option in the ethnic group question was unacceptable and that the community preferred to have a Jewish option only in the religion question (HM Government 2018). Moreover, stakeholder engagement with the Board of Deputies of British Jews and the Institute for Jewish Policy Research revealed that there were concerns around continuity of data. ONS therefore decided not to recommend a specific Jewish response option in the 2021 Census ethnic group question.

With respect to 'Sikh', there were differing views within the Sikh population regarding a specific response option in the 2021 Census. A survey of Gurdwaras that enquired about acceptance of a Sikh ethnic group tick-box showed a high level of acceptance for inclusion. However, independent focus group research undertaken for ONS amongst Sikh participants from major cities found that the inclusion of a Sikh tick-box, without other religion tick-boxes, within the ethnic group question was unacceptable. Moreover, some participants felt confused about having to choose between an Indian and Sikh identity. Further, additional ONS quantitative survey findings found no evidence that the religion and ethnic group questions were capturing different Sikh populations. So again, ONS decided against adding a specific Sikh response option.

The 2011 England and Wales Census identified 2.7 million Muslims in the religion question, mainly concentrated in the Pakistani (38\%), Bangladeshi (15\%), Indian (7\%), Black African (8\%), and Arab $(7 \%)$ ethnic groups. In situations where an open response option is used to capture ethnic group, there is some evidence that respondents will identify as Muslim. For example, the 2001 People, Families and Community Survey (Citizenship Survey) asked respondents to describe their ethnic group in their own words towards the end of the questionnaire, respondents having identified at the beginning using the 2001 Census ethnicity classification. 3.4\% of Indians, 20.5\% of Pakistanis, and $15.2 \%$ of Bangladeshis mentioned Muslim/Moslem/Islam/Islamic in their responses, but only $1.8 \%$ of Black Africans ${ }^{15}$. This preparedness amongst Asians to include a Muslim identity in their free-text ethnic group responses has not impacted on their acceptability and use of the Census pre-designated categories, nor has it translated into a demand for inclusion of a 'Muslim' category in the ethnic group question. In the wider society 'Muslim' has widespread saliency as a collective term of religious identity, both as a self-descriptor and a term of identification by others. A concerning development over recent decades has been a rise in anti-Muslim prejudice (termed 'Islamophobia'). This has taken the form of both an extreme level of generalization and as anti-Arab and anti-Asian sentiment.

\section{Discussion}

Collective terms for minority ethnic groups, including acronyms and abbreviations, are frequently distant from group identifiers or internal definitions, not least because they are collective and not

15 Home Office People, Families and Communities Survey (renamed Citizenship Survey) 2001. Data set SN 4754 accessed via the Economic and Social Data Service and analyzed in SPSS. 
specific to groups. Moreover, as social categories they are devised and brought into widespread use by a range of actors such as official bodies, advocacy and interest groups, the media, and, indeed, the wider society. This distance between such definitions and group identifiers creates a space for the emergence of representational meanings. One of the most widespread in Britain is that of 'political blackness' that anti-racists, racial justice advocates, and sociologists fostered from the 1960s. This conceptualization enfolded under one label all those groups who were perceived as potential victims of white racism. The idea that 'black' was an inclusive category that established a political solidarity between Afro-Caribbean and Asian groups, facilitated by class struggle, was promoted to amplify the effectiveness of anti-racist activism.

This political identity was likely to have been carried over into the acronym 'BME', given the way it distinguishes between 'black' and 'minority ethnic'. Indeed, terminology that specified 'black and Asian' - notably, the 'BAME' acronym-was criticized as a divisive strategy that diluted the political notion of 'blackness' (Sudbury 1998). The conflictual nature of these terms-the lack of support for 'political blackness' amongst Asians and the widespread lack of understanding of the acronyms-stems from their failure to draw on group internal definitions. In some cases, this usage of collective terminology can create ethical dilemmas, as when it is offensive (e.g., 'Non-White', 'Oriental') or when self-ascribed identities declared in data collection processes are administratively conscripted into little understood collective algorithms. This may explain why, although infrequently used in Britain, other terms such as 'people of colour' and 'women of colour' have emerged, being more strongly embedded as group terms rather than substantively externally imposed labels.

The terminology for particular ethnic groups is more likely to be regarded as consensual and acceptable to those described by it as it tends to adopt ethnic group terminology agreed for the decennial censuses. Such terminology is only approved after extensive testing, including cognitive research, focus groups, small-scale tests, and large-scale trials, including the Census Rehearsal. Increasingly, members of minority ethnic groups have been involved in such research, both as participants and also through community advisory groups. Nearly all members of the population are able to answer the ethnic group question, not least because of the generous provision of free-text fields, even if some of the pre-designated options may be only partially or situationally meaningful for them or when different terms may have some saliency as group identifiers. There are now few exceptions to this concordance between terminology favoured by minority ethnic groups and that used by census and statistical agencies, as both are implicated in each other. Indeed, census terminology may be enabling of group identities. As Petersen (1987) put it: 'Few things facilitate a category's coalescence into a group so readily as its designation by an official body'.

Unfortunately, acronyms like 'BME' and 'BAME' appear to be gaining in reality with respect to usage by government and the media, in spite of advice against such usage in official guidance. Greater scrutiny and monitoring of these terms is needed, as part of a wider public debate on appropriate terminology. There is evidence that terms like 'minority ethnic' and 'ethnic minority' are widely accepted and understood. When there is a need to identify the constituent groups in collective terms, the use of accurate description to delineate these population groups is recommended.

\section{Materials and Methods}

Structured searches were undertaken on citation databases of peer-reviewed literature-ISI Web of Knowledge and SCOPUS - to identify papers on ethnic/racial terminology and nomenclature. Additionally, the PsycINFO, POPLINE, EMBASE, and Google Scholar databases of abstracts of literature were searched. The full text was retrieved of all relevant papers. Searches were also undertaken on the websites of the Office for National Statistics, National Records of Scotland, and the United States Census Bureau for documents on census categorization and classifications.

From an empirical point of view, there is a lack of evidence at a population level on the preferred terms, or terms of choice, of members of minority and majority ethnic groups. A small number of surveys have explicitly sought the preferred ethnic/racial terms of participants from different ethnic 
groups, though this usually takes the form of choosing from a schedule of predesignated terms (Tucker et al. 1996). In some such surveys, categories such as 'some other term' and 'no preference' can be significant. Only rarely has information been sought on respondents' self-descriptors through an unprompted free-text question (Aspinall and Song 2013). There is also an evidence base relating to free-text responses in race/ethnicity classifications, though these are invariably part of a set including predesignated options. Such responses are therefore a residual set for those who do not find the listed categories acceptable. Other evidence derives from telephone and online polls that invite participants to choose their preferred term, though such evidence cannot be set in the context of a defined population. This paucity of evidence makes it difficult to evaluate the efficacy of racial/ethnic terminology from the viewpoint of acceptability by those being described. In practice this evaluative task is generally achieved in Britain through the process of testing in census development programmes, that is, a reactive process in which respondents are invited to express their views on the terms offered by officialdom.

A further challenge lies in the paucity of data that can be used to delineate the genealogies or etymologies of terminology. Most ethnic/racial terms in use are the outcome of long-term processes involving the derivation of the terms, their adoption by official agencies such as census and statistical offices, the media, and other influencers, and their wider acceptance in the community. Some of these processes involve pressures towards particularity or granularity, while others favour the pursuit of aggregation or lumping. Terminology over time may gain in saliency or wane in response to wider social and political circumstances. Our ability to track these pathways depends on the availability of registries that record the use of terminology over time. Such resources are scarce as they require historical full-text corpora from which trend data can be derived, yet the churn of material on the internet reduces its utility for such purposes. Google N-grams have provided this service for books, though this source lacks utility, as it cannot partition the capture of terminology by country of usage (only by the generalized language of the corpora); further, the number of occurrences of specific terminology is frequently too few to generate N-grams. Similarly, the full-text of newspapers, both broadsheets and tabloids, yield too few cases for reliable trends in media usage of terminology to be compiled. However, a few sources offer possibilities, including the written records of the proceedings of the UK parliament, which have been used in this study in relation to official usage. The various databases of published literature in the humanities and sciences (such as SCOPUS and Web of Science) can also be used to track scholarly usage of terminology, though without specificity of country of usage.

Funding: This research received no external funding.

Conflicts of Interest: The author declares no conflict of interest.

\section{References}

Aspinall, Peter. 2002. Collective terminology to describe the minority ethnic population: The persistence of confusion and ambiguity in usage. Sociology 36: 803-16. [CrossRef]

Aspinall, Peter. 2005. Language Matters. Journal of Health Services Research E Policy 10: 57-59.

Aspinall, Peter. 2013. The social evolution of the term 'half-caste' in Britain: The paradox of its use as both derogatory racial category and self-descriptor. Journal of Historical Sociology 26: 503-26. [CrossRef]

Aspinall, Peter, and Miri Song. 2013. Mixed Race Identities. Basingstoke: Palgrave Macmillan.

Bannerji, Himani. 2000. The paradox of diversity: The construction of a multicultural Canada and 'Women of Color'. Women's Studies International Forum 23: 537-60. [CrossRef]

Bradby, Hannah. 1995. Ethnicity: Not a black and white issue. A research note. Sociology of Health and Illness 17: 405-17. [CrossRef]

Bunglawala, Zamila. 2019. Please, Don't Call Me BAME or BME! Civil Service Blog, July 8. Available online: https://civilservice.blog.gov.uk/2019/07/08/please-dont-call-me-bame-or-bme/ (accessed on 1 July 2020).

Cannadine, David. 2013. The Undivided Past: History Beyond Our Differences. London: Allen Lane.

Hacking, Ian. 1986. 'Making Up People'. In Reconstructing Individualism: Autonomy, Individuality, and the Self in Western Thought. Edited by Thomas Heller, Morton Sosna and David Wellbery. Stanford: Stanford University Press, pp. 222-36. 
Hall, Stuart. 1997. The work of representation. In Representation: Cultural Representations and Signifying Practices. Edited by Stuart Hall. London: Sage Publications Inc.

HM Government. 2018. Help Shape Our Future. The 2021 Census of Population and Housing in England and Wales. Cm 9745; London: HMSO.

Jenkins, Richard. 1996. Social Identity. London and New York: Routledge.

Jivraj, Stephen, and Ludi Simpson. 2015. Ethnic Identity and Inequalities in Britain. The Dynamics of Diversity. Bristol: Policy Press.

Johnson, Mark RD, Raj S Bhopal, David Ingleby, L. Gruer, and R. S. Petrova-Benedict. 2019. A glossary for the first World Congress on Migration, Ethnicity, Race and Health. Public Health 172: 85-88. [CrossRef] [PubMed]

Joseph, Ralina L. 2013. Transcending Blackness. Durham and London: Duke University Press.

Judicial College. 2018. Equal Treatment Bench Book. London: Judicial College.

Kobayashi, Audrey. 1993. Representing Ethnicity: Political Statistexts. In Challenges of Measuring an Ethnic World: Science, Politics and Reality. Proceedings of the Joint Canada-United States Conference on the Measurement of Ethnicity; Washington, DC: US Government Printing Office, pp. 513-25.

Lammy, David. 2017. The Lammy Review. An Independent Review into the Treatment of, and Outcomes for, Black, Asian and Minority Ethnic Individuals in the Criminal Justice System; London: Ministry of Justice.

Madowitz, Jennifer, and Kerri N. Boutelle. 2014. Ethical Implications of Using the Term "Non-white" in Psychological Research. Ethics \& Behavior 24: 306-10.

Modood, Tariq, Sharon Beishon, and Satnam Virdee. 1994. Changing Ethnic Identities. London: Policy Studies Institute.

Modood, Tariq, Richard Berthoud, Jane Lakey, James Nazroo, Patten Smith, Satnam Virdee, and Sharon Beishon. 1997. Ethnic Minorities in Britain: Diversity and Disadvantage. The Fourth National Survey of Ethnic Minorities. London: Policy Studies Institute.

Pendakur, Ravi. 1993. Visible minority as a redefinition of race. In International Population Conference/Congres International de la Population: Montreal, Vol. 3. Liege: International Union for the Scientific Study of Population [IUSSP], pp. 469-82.

Petersen, William. 1987. Politics and the measurement of ethnicity. In The Politics of Numbers. Edited by William Alonso and Paul Starr. New York: Russell Sage Foundation, pp. 187-234.

Public Health England. 2020. Beyond the Data: Understanding the Impact of COVID-19 on BAME Groups; London: Public Health England.

Saeed, Amani, Elliott Rae, Rob Neil, Vivienne Connell-Hall, and Frank Munro. 2019. To BAME or Not to BAME: The Problem with Racial Terminology in the Civil Service (in 'Opinion'). Available online: https://www. civilserviceworld.com/articles/opinion/bame-or-not-bame-problem-racial-terminology-civil-service (accessed on 1 July 2020).

Said, Edward W. 2003. Orientalism. London: Penguin Books. First published by Routledge \& Kegan Paul Ltd. 1978.

Sudbury, Julia. 1998. 'Other Kinds of Dreams': Black Women's Organisations and the Politics of Transformation. London and New York: Routledge.

Tucker, Clyde, Ruth McKay, Brian Kojetin, Roderick Harrison, Manuel de la Puente, Linda Stinson, and Ed Robison. 1996. Testing Methods of Collecting Racial and Ethnic Information: Results of the Current Population Survey Supplement on Race and Ethnicity; Washington, DC: Bureau of Labor Statistics.

US Congress. 2016. House Bill H.R. 4238. Removing "Oriental” and Other Dated Terms to Describe Minorities from Federal Laws. Passed 20 May 2016. Available online: https://www.congress.gov/bill/114th-congress/ house-bill/4238/text (accessed on 1 July 2020).

Yuen, Edward. 1997. Social movements, identity politics and the genealogy of the term 'People of Color'. New Political Science 19: 97-107. [CrossRef]

(C) 2020 by the author. Licensee MDPI, Basel, Switzerland. This article is an open access article distributed under the terms and conditions of the Creative Commons Attribution (CC BY) license (http://creativecommons.org/licenses/by/4.0/). 